Supporting information for

\title{
Analysis of Conjugated Fatty Acid Isomers by the Paternò-Büchi Reaction and Trapped Ion Mobility Mass Spectrometry
}

Xiaobo Xie ${ }^{\dagger}$ and $\mathrm{Yu} \mathrm{Xia*}{ }^{*} \dagger$

${ }^{\dagger}$ Department of Chemistry, Tsinghua University, Beijing 100084, China

1. On-line PB-ESI-MS/MS and PB-TIMS-MS Setup ...........................................................................

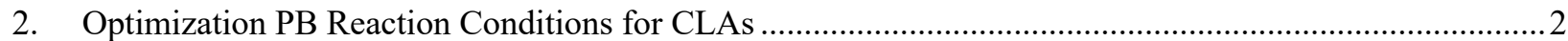

3. TIMS-MS/MS and LC-MS/MS Characterization of PB products ............................................................. 4

To whom correspondence should be addressed:

Prof.YuXia, xiayu@mail.tsinghua.edu.cn 
1. On-line PB-ESI-MS/MS and PB-TIMS-MS Setup

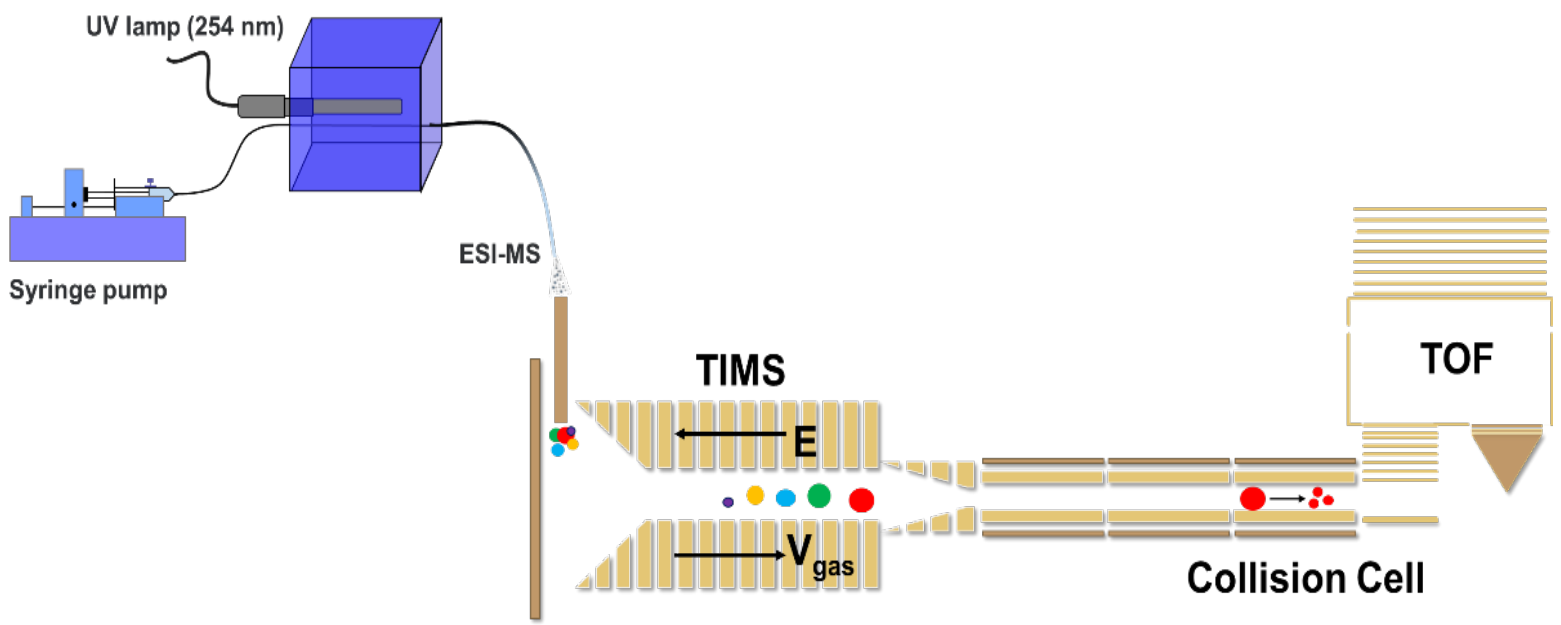

Figure S1. Schematic diagram of on-line PB-ESI-MS/MS and TIMS-TOF MS instrument.

2. Optimization PB Reaction Conditions for CLAs

Table S1. The experimental masses and exact masses for all detected ions using $\mathrm{D}_{0}$-acetone as $\mathrm{PB}$ reagent and spray solvent.

\begin{tabular}{llll}
\hline Experimental mass & Element Composition & Exact mass & Error (ppm) \\
\hline 279.2331 & $\mathrm{C}_{18} \mathrm{H}_{31} \mathrm{O}_{2}^{-}$ & 279.2330 & 0.4 \\
295.2279 & $\mathrm{C}_{18} \mathrm{H}_{31} \mathrm{O}_{3}^{-}$ & 295.2279 & 0 \\
309.2434 & $\mathrm{C}_{19} \mathrm{H}_{33} \mathrm{O}_{3}^{-}$ & 309.2435 & -0.3 \\
321.2433 & $\mathrm{C}_{20} \mathrm{H}_{33} \mathrm{O}_{3}^{-}$ & 321.2435 & -0.6 \\
323.2589 & $\mathrm{C}_{20} \mathrm{H}_{35} \mathrm{O}_{3}^{-}$ & 323.2592 & -0.9 \\
325.2744 & $\mathrm{C}_{20} \mathrm{H}_{37} \mathrm{O}_{3}^{-}$ & 325.2748 & -1.2 \\
335.2589 & $\mathrm{C}_{21} \mathrm{H}_{35} \mathrm{O}_{3}^{-}$ & 335.2592 & -0.9 \\
337.2744 & $\mathrm{C}_{21} \mathrm{H}_{37} \mathrm{O}_{3}^{-}$ & 337.2748 & -1.5 \\
351.2900 & $\mathrm{C}_{22} \mathrm{H}_{39} \mathrm{O}_{3}^{-}$ & 351.2905 & -1.4 \\
353.2694 & $\mathrm{C}_{21} \mathrm{H}_{37} \mathrm{O}_{4}^{-}$ & 353.2697 & -0.8 \\
365.2696 & $\mathrm{C}_{22} \mathrm{H}_{37} \mathrm{O}_{4}^{-}$ & 365.2697 & -0.3 \\
367.2851 & $\mathrm{C}_{22} \mathrm{H}_{39} \mathrm{O}_{4}^{-}$ & 367.2854 & -0.8 \\
379.2854 & $\mathrm{C}_{23} \mathrm{H}_{39} \mathrm{O}_{4}^{-}$ & 379.2854 & 0 \\
381.3009 & $\mathrm{C}_{23} \mathrm{H}_{41} \mathrm{O}_{4}^{-}$ & 381.3010 & -0.3 \\
393.3014 & $\mathrm{C}_{24} \mathrm{H}_{41} \mathrm{O}_{4}^{-}$ & 393.3010 & 1.0 \\
395.3167 & $\mathrm{C}_{24} \mathrm{H}_{43} \mathrm{O}_{4}^{-}$ & 395.3167 & 0 \\
\hline
\end{tabular}


a Acetone/water $=1: 2,4 \mathrm{~s}$

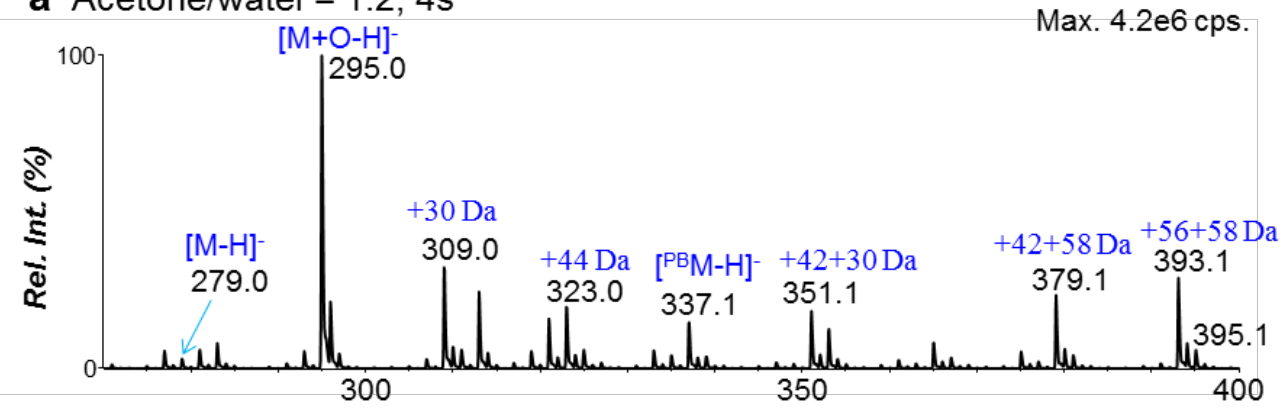

b Acetone/water $=1: 1,4 \mathrm{~s}$

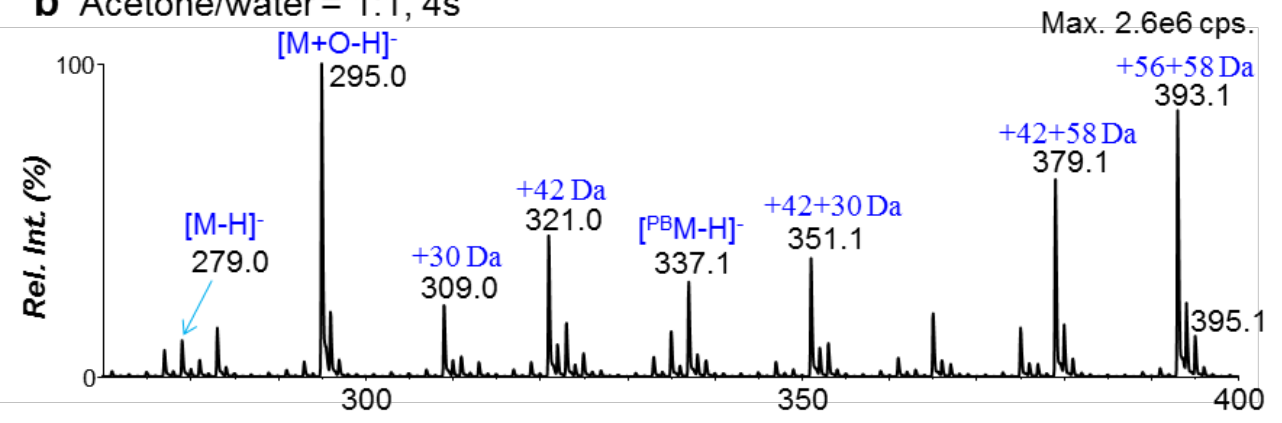

C Acetone/water $=2: 1,4 \mathrm{~s}$

Max. $4.5 \mathrm{e} 6 \mathrm{cps}$.

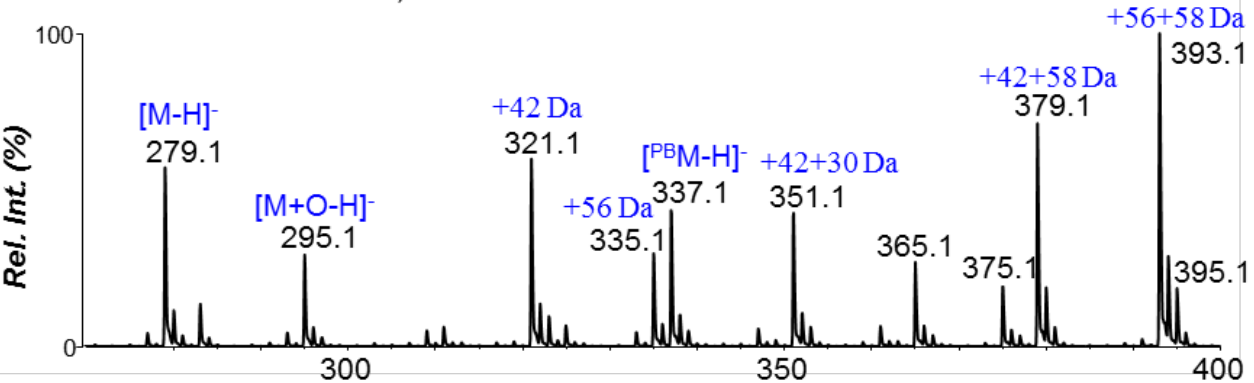

d Acetone/water $=3: 1,4 \mathrm{~s}$

Max. $1.0 \mathrm{e} 6 \mathrm{cps}$.

$[\mathrm{M}-\mathrm{H}]^{-}$

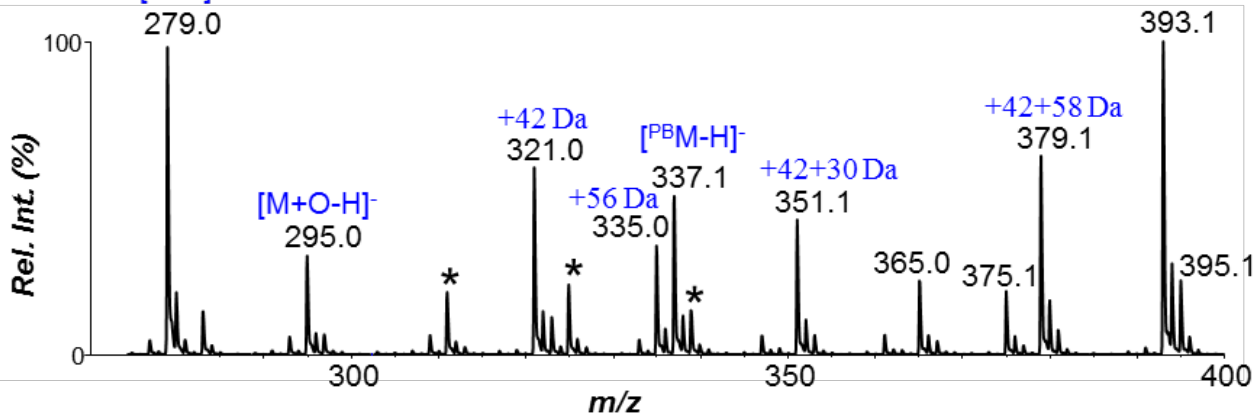

Figure S2. PB-MS spectra of FA 18:2 $(10 E, 12 Z)(10 \mu \mathrm{M})$ in acetone-water binary solvent system, (a) acetone $/$ water $=1: 2$, (b) acetone $/$ water $=1: 1$, (c) acetone $/$ water $=2: 1$, and (d) acetone $/$ water $=3: 1(\mathrm{v} / \mathrm{v})$. 

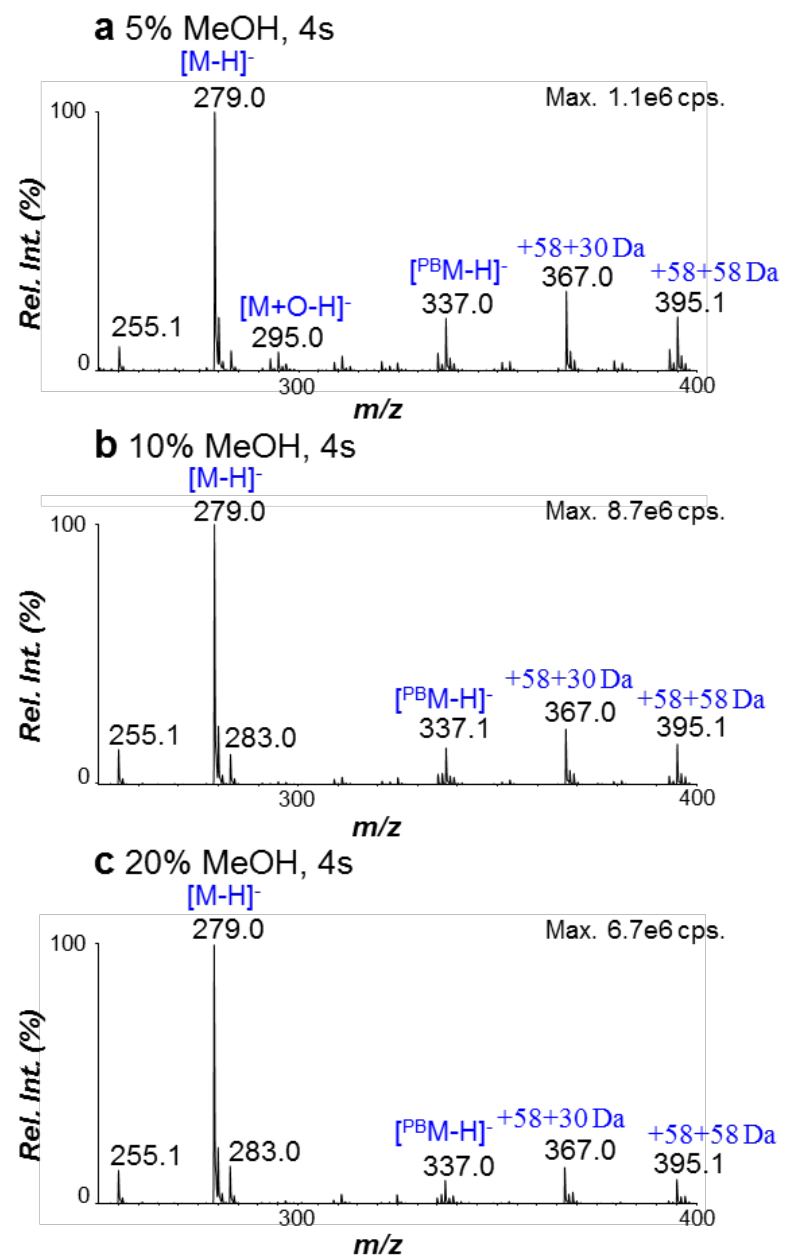

Figure S3. PB-MS spectra of CLA 18:2(10E,12Z) in acetone-water $(3 / 1, v / v)$ binary solvent system containing different ratio of methanol (a) $5 \%$, (b) $10 \%$, and (c) $20 \%$.

\section{TIMS-MS/MS and LC-MS/MS Characterization of PB products}

LC-MS/MS analyses were conducted on a Shimadzu LC-20AD system (Kyoto, Japan) coupled with a highresolution X500R QTOF system (Applied Biosystems, Foster City, CA, USA). A C18 column $(150 \mathrm{~mm} \times 3.0$ mm i.d., $2.7 \mu \mathrm{m}$ particle size, Ascentis ${ }^{\circledR}$ Express) was used for chromatographic separation with a flow rate at $0.3 \mathrm{~mL} / \mathrm{min}$. The PB reaction solution was collected for LC-MS analysis. Injection volume was set to $2 \mu \mathrm{L}$. Mobile phase consisted of acetonitrile with $0.1 \%$ formic acid $(v / v, \mathrm{~A})$ and ammonium formate buffer (10 $\mathrm{mM}$, B). Gradient elution was used as follows: $80 \%$ B (3 min), 80\%-83\% B (3-7 min), 83\%-86\% B (7-13 min), $86 \%-89 \%$ B (13-18 min), and 89\%-95\% B (18-20 min). At the end of elution, the gradient was set back to $80 \%$ $\mathrm{B}$ and the system was allowed to equilibrate. 
a PB-TIMS-MS²@30eV

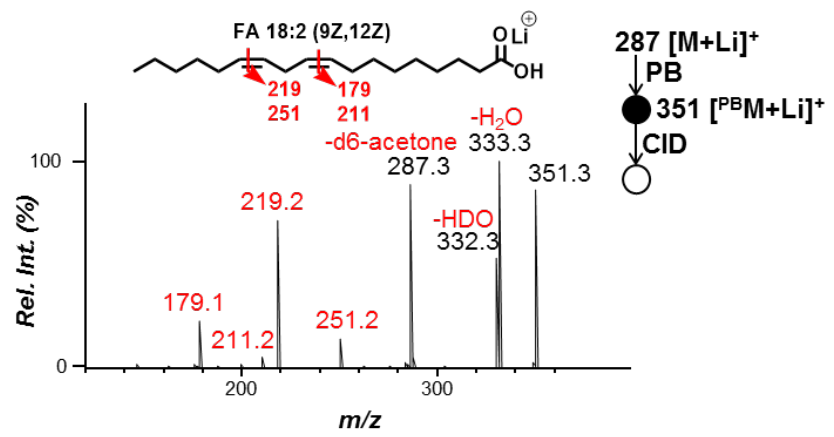

b PB-TIMS-MS²@35eV

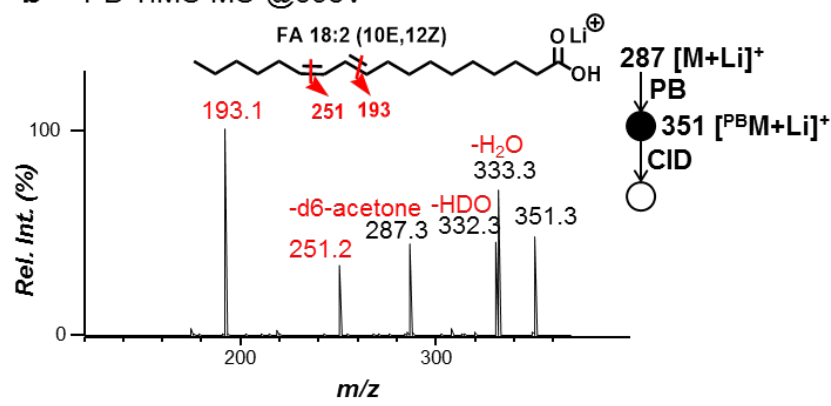

Figure S4. Positive ion mode PB-TIMS-MS/MS spectra of (a) nonconjugated LA 18:2 (9Z,12Z) and (b) CLA 18:2 $(10 E, 12 Z)\left(5 \mu \mathrm{M}\right.$ each in $\mathrm{D}_{6}$-acetone/ $\mathrm{H}_{2} \mathrm{O} / \mathrm{MeOH}=68 / 22 / 10, v / v / v$ with $1 \mathrm{mM} \mathrm{LiCl}$ added $)$.

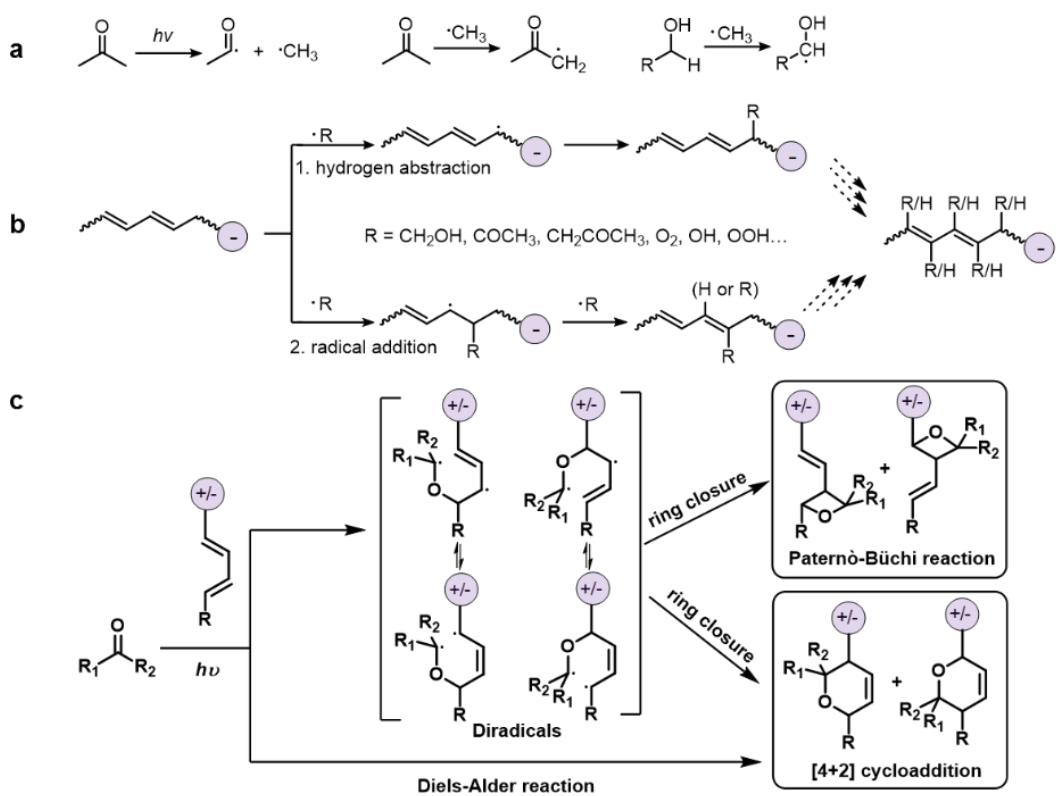

Scheme S1. (a) Radicals generated during the PB reactions; (b) Possible mechanisms of the formation of side products; (c) Possible mechanism for the formation of six-membered ring products. 

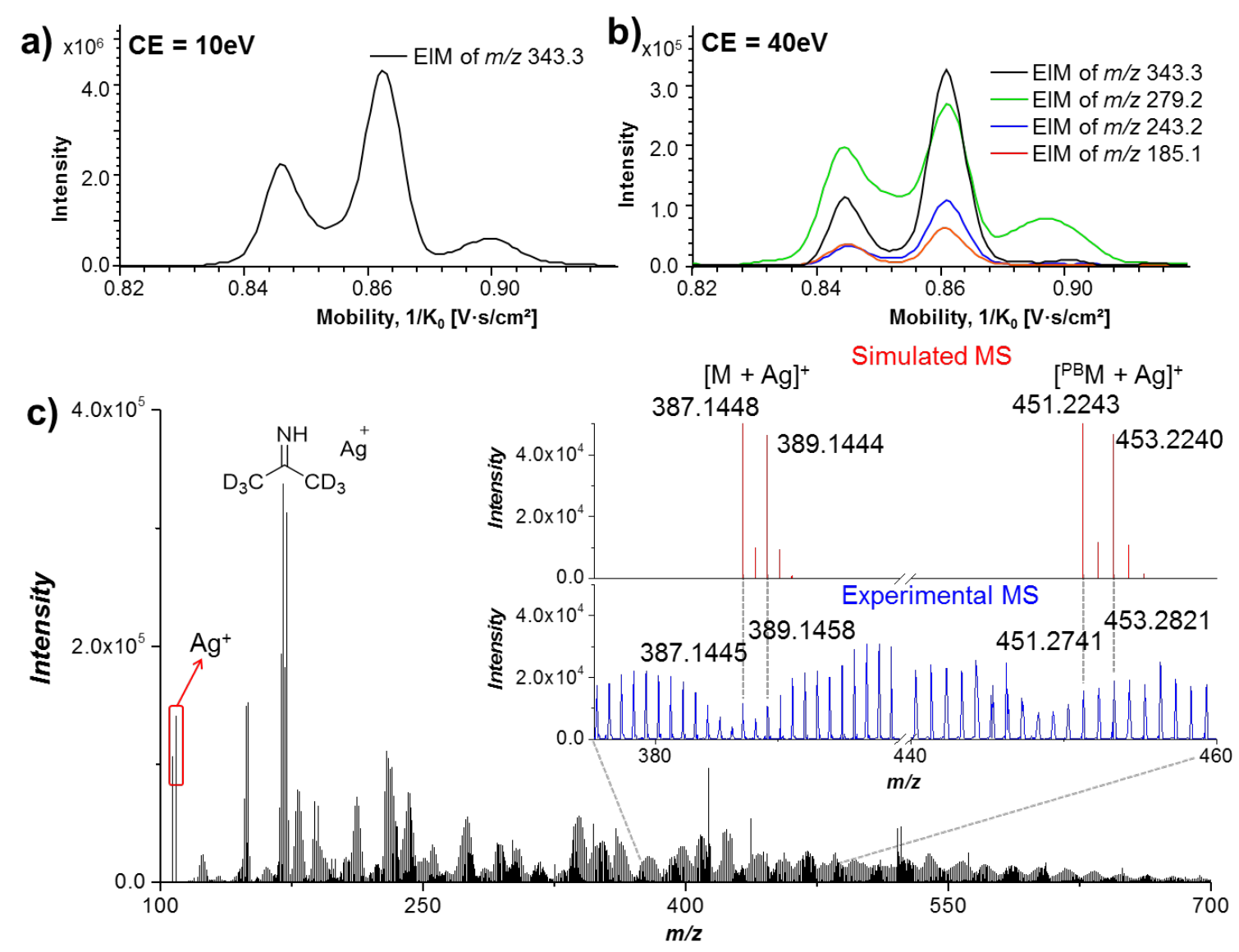

Figure S5. (a) EIM of $\left[{ }^{\mathrm{PB}} \mathrm{M}-\mathrm{H}\right]^{-}$at $\mathrm{m} / \mathrm{z} 343.3$ when CID energy is $10 \mathrm{eV}$; (b) EIMs of $\mathrm{C}=\mathrm{C}$ diagnostic fragment ions ${ }^{12} \mathrm{~F}_{\mathrm{O}}(\mathrm{m} / \mathrm{z} 243.2)$ and ${ }^{10} \mathrm{~F}_{\mathrm{A}}(\mathrm{m} / \mathrm{z} 185.1),[\mathrm{M}-\mathrm{H}]^{-}\left(\mathrm{m} / z\right.$ 279.2) and $\left[{ }^{\mathrm{PB}} \mathrm{M}-\mathrm{H}\right]^{-}(\mathrm{m} / z$ 343.3) when CID energy is $40 \mathrm{eV}$. (c) PB-MS ${ }^{1}$ spectra obtained in ESI positive ion mode with $100 \mu \mathrm{M} \mathrm{AgNO}_{3}$ added. Insets: an enlarged view of experimental PB-MS spectrum and simulated MS spectrum of $[\mathrm{M}+\mathrm{Ag}]^{+}(\mathrm{m} / z 387.1448$ and 389.1444) and $\left[{ }^{\mathrm{PB}} \mathrm{M}+\mathrm{Ag}\right]^{+}(\mathrm{m} / \mathrm{z} 451.2243$ and 453.2240$)$ at a mass range of $\mathrm{m} / \mathrm{z} 375$ to 460 with a break from $\mathrm{m} / \mathrm{z} 400$ to 440. 


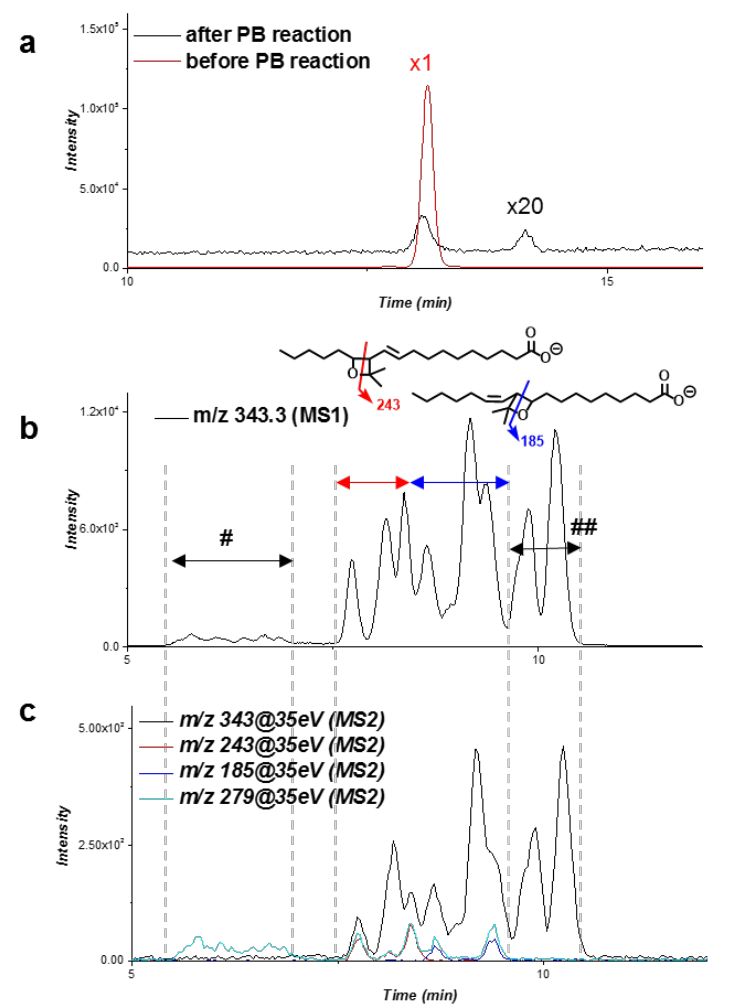

Figure S6. LC-MS/MS analysis of CLA 18:2 (10E,12Z) $\left(10 \mu \mathrm{g} / \mathrm{mL}\right.$ in a $\mathrm{D}_{6}$-acetone/ $\mathrm{H}_{2} \mathrm{O} / \mathrm{MeOH}=68 / 22 / 10$, $v / v / v$ ). (a) Extracted ion chromatograms (EICs) of [M-H] $]^{-}$at $m / z 279.2$ before PB reaction (black line) and after PB reaction (red line). The total conversion yield is calculated as $98.8 \%$, in which cis-trans isomerization contributes $0.6 \%$. (b) EIC of the deprotonated PB products at $\mathrm{m} / \mathrm{z} 343.3$ in $\mathrm{MS}^{1}$ spectrum; (c) EICs of the precursors at $\mathrm{m} / \mathrm{z} 343.3$ and the fragments at $\mathrm{m} / \mathrm{z} 279.2,185.1$ and 243.2 in the PB-LC-MS ${ }^{2}$ spectrum. The symbols \# (more labile) and \#\# (rigid) represent other side products.
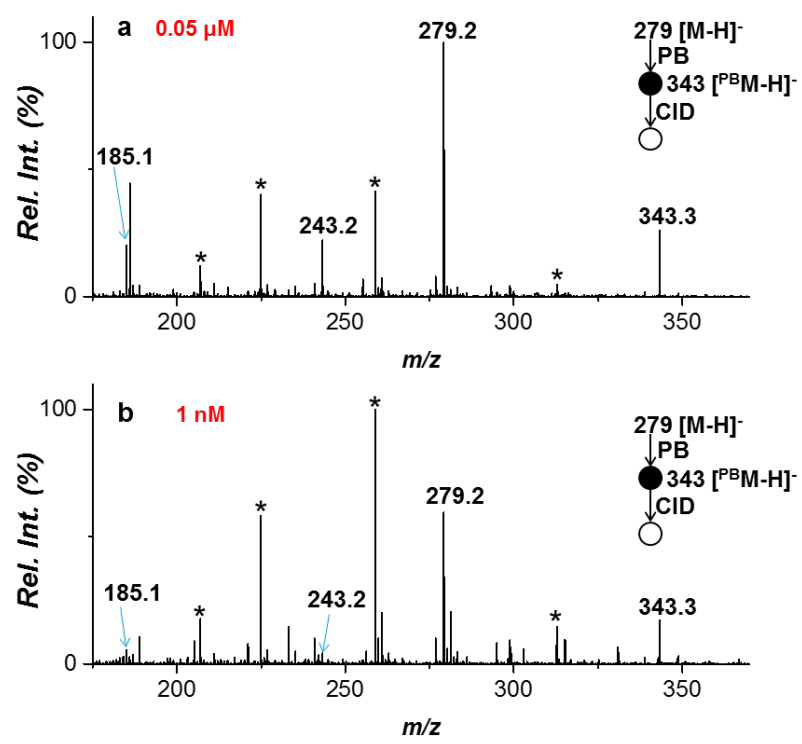

Figure S7. Negative ion mode PB-MS/MS spectrum obtained from CLA 18:2(10E,12Z) in a $\mathrm{D}_{6}$-acetone/ $\mathrm{H}_{2} \mathrm{O} / \mathrm{MeOH}$ ( $v / v / v, 68 / 22 / 10)$ solvent system: (a) $0.05 \mu \mathrm{M}$ and (b) $1 \mathrm{nM}$. 

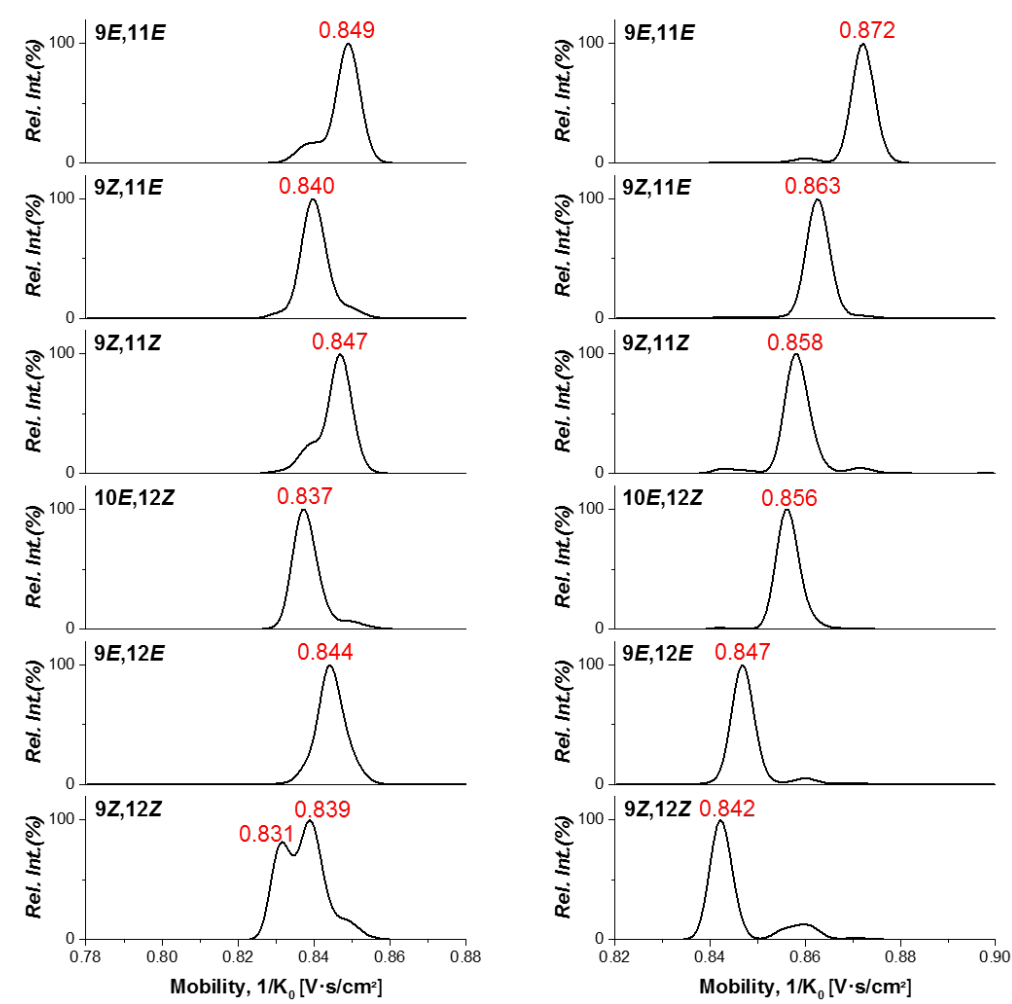

Figure S8. EIMs of [M-H] ${ }^{-}$at $m / z 279.2$ (left column) and $\left[\mathrm{M}+{ }^{109} \mathrm{Ag}\right]^{+}$at $m / z 389.1$ (right column). Deprotonated ions of FA 16:0 at $m / z 255.1\left(1 / \mathrm{K}_{0}: 0.807\right)$ and FA 18:0 at $\mathrm{m} / z 283.2\left(1 / \mathrm{K}_{0}: 0.8507\right)$ are used as internal standards (IS) for correcting the error of $1 / \mathrm{K}_{0}$ in negative ion mode, and the measured $1 / \mathrm{K}_{0}$ values are relatively stable in one day using the same method.
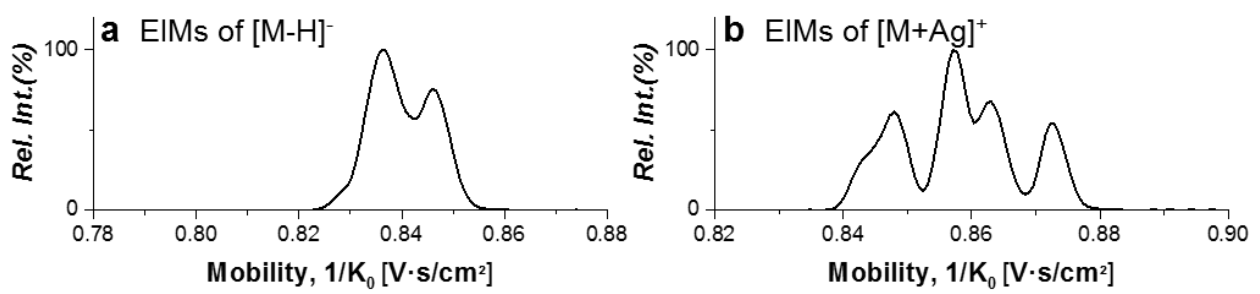

Figure S9. EIMs of an equal molar mixture of six fatty acids (FA 18:2(9Z,12Z), FA 18:2(9E,12E), FA 18:2(9Z,9E), FA 18:2(9Z,11Z), FA 18:2(9E,11E), and FA 18:2(10E,12Z) with a total concentration at $1 \mu \mathrm{M})$. (a) $[\mathrm{M}-\mathrm{H}]^{-}$at $m / z 279.2 ;(\mathrm{b})\left[\mathrm{M}+{ }^{109} \mathrm{Ag}\right]^{+}$at $m / z 389.1$. 